\title{
PENGARUH DISIPLIN KERJA, LINGKUNGAN KERJA,DAN PENILAIAN PRESTASI \\ KERJA TERHADAP KINERJA KARYAWAN PADA PT. VMC FISHING TACKLE INDONESIA
}

\author{
Yannik Ariyati' ${ }^{1)}$, Leni Primasari ${ }^{2}$ \\ Program Studi Manajemen, Fakultas EkonomiUniversitas Riau Kepulauan Batam \\ yannik_ariyati@yahoo.co.id ${ }^{\mathbf{1}}$, \\ Program Studi Manajemen, Fakultas EkonomiUniversitas Riau Kepulauan Batam \\ leniprimasari@gmail.com²)
}

\begin{abstract}
ABSTRAK
Didalam dunia industri pengembangan MSDM sangat perlu dilakukan mengingat adanya revolusi industri 4.0 dan yang mana akan terus berkembang. Tujuian meneliti adalah apakah pengaruh disiplin, lingkungan, dan penilaiam prestasi kerja untuk kinerja setiap karyawan di PT. VMC Fishing Tackle Indonesia. Penelitian ini memakai sebuah metode penelitian secara kuantitatif. Populasi penelitian ini ialah seluruh karyawan PT. VMC Fishing Tackle Indonesia berjumlah 98 orang. Teknik pengambilan sampel menggunakan teknik Sampling Jenuh. Data didapat menggunakan angket yang telah diuji validitas dan reliabilitas. Maka didapatkan hasil: adanya pengaruh untuk disiplin, lingkungan, dan penilaian prestasi kerja pada kinerja setiap karyawan, hal ini bisa di lihat dari hasil Variabel Disiplin Kerja, dari Lingkungan Kerja T hitung $=-0,861<\mathrm{t}$ tabel $=(1,66055), \mathrm{T}$ hitung $=4,535>\mathrm{T}$ tabel $=1,66055$, dan dari Penilaian Prestasi Kerja $\mathrm{T}$ hitung $=2,128>\mathrm{T}$ tabel $=1,66055$.
\end{abstract}

Kata Kunci : disiplin kerja, lingkungan kerja, penilaian prestasi kerja.

\begin{abstract}
In the industrial world the development of HRM is very necessary considering the 4.0 industrial revolution and which will continue to grow. Tujuian research is whether the influence of discipline, environment, and performance appraisal for the performance of each employee at PT. VMC Fishing Tackle Indonesia. This research uses a quantitative research method. The population of this research is all employees of PT. VMC Fishing Tackle Indonesia totaling 98 people. The sampling technique uses saturated sampling technique. Data obtained using a questionnaire that has been tested for validity and reliability. Then the results are obtained: the influence for discipline, environment, and performance appraisal on the performance of each employee, this can be seen from the results of the Work Discipline Variable, from the Work Environment $T$ count $=-0.861<t$ table $=(1.66055), T$ count $=4,535>T$ table $=1,66055$, and from the Job Performance Assessment T count $=2.128>$ T table $=1.66055$.
\end{abstract}

Keywords: work discipline, work environment, performance appraisal 
Disiplin kerja yaitu komunikasi yang terjadi sebuah proses para manajer terhadap karyawan dimana karyawan ini siap dalam mengubah baik prilaku maupun tindakan serta norma yang berlaku di dalam perusahaan tersebut. Demikian juga jika perusahaan mengalami, semakin tinggi pula prestasi kerja yang akan dicapainya. Sehingga displin karyawan memiliki peran yang kuat, sehingga akan memperoleh hasil yang baik dan optimal pula. Kepribadian merupakan faktor yang dapat di pengaruh terhadap seseorang karyawan, begitu juga lingkangan juga termasuk yang dapat mempengaruhi karena kedua ini memilki nilai yang erat yang setiap orang pasti mempunyai. Faktor kepribadian salah satu faktor yang termasuk sulit di lakukan oleh para manajer namun harus dimilki setiap manajer, karena manajer adalah pengaruh kuat kepada bawahan. Ada beberapa yang harus di lakukan setiap manajer bagaimana membuat perubahan terhadap kedisplinan bagi karyawan. Antara lain seperti sanksi dimana ini akan menjadi efek jera terhadap karyawan yang melanggar disiplin, sehingga menjadi nilai penting yang tidak bisa di langgar sehingga bisa mengubah sikap setiap karyawan. Selain itu bisa dilakukan dengan adanya pemberian motivasi serta semangat dengan cara di berikan sebuah hadiah yang di sebut bonus untuk tambahan gaji. Sehingga setiap karyawan akan mengalami semangat. Kinerja dimana ini akan dapat membuat pengaruh terhadap lingkungan di tempat kerja itu sendiri. Organisasi memiliki peran induk dalam lingkungan kerja yang nyaman serta kondusif yang akan membuat karyawan terpancing yang menghasilkan karyawan yang bekerja keras dan produktif. Meskipun lingkungan kerja tidak melaksanakan proses kerja dalam perusahaan akan tetapi lingkungan kerja mempunyai pengaruh langsung terhadap karyawan. Seiring dengan perubahan yang terus terjadi pada setiap perusahaan hal yang paling jarang diperhatikan oleh perusahaan ialah lingkungan tempat kerja karyawannya yang seharusnya lingkungan kerja juga harus ikut berubah seiring dengan perubahan yang terjadi.Dimana karyawan itu sendiri yang merasakan keadaan atas kondisi dilingkungan tempat mereka bekerja yang membuatnya nyaman atau tidak dalam bekerja. Tersedia tempat kerja yang nyaman akan ada hasil kepuasan terhadap karyawan setiap pekerjaan akan dampak menjadi kesan yang sangat terdalam dan muncul kinerja yang baik. Dalam lingkungan kerja pasti akan ada dua dimensi antara lain fisik (pewarnaan ruangan, pencahayaan, kebersihan, tata ruang,dll) dan non fisik (kesejahteraan karyawan, suasana kerja, hubungan antar karyawan,dll). Organisasi harus bisa mensiapkan kedua dimensi tersebut dalam keadaan baik sehingga mampu membuat para karyawan agar mampu bisa dapat saling kerja sama dan tetap produktif karena manajer dan karyawan memilki tujuan yang sama dalam memajukan organisasi.

Lingkungan kerja yang baik akan menghasilkan kenyamanan yang dapat mendukung dalam bekerja tentunya akan menjadi acuan semangat, tidak gampang sakit dan dapat menghasilkan pengaruh displinan untuk karyawan. Perusahaan harus melakukan penilaian yang dapat tahu sejauh mana prestasi dan kualitas setiap karyawan dalam melakukan tugas yang di tetapkan tersebut. Setiap karyawan yang punyai rasa prestasi kerjanya tinggi. Maka mereka sangat ingin promosi jabatan, karena di anggap bahwa itu adalah penghargaan untuk keberhasilannya menunjukkan prestasi kerja yang tinggi sekaligus sebagai keberhasilan potensi karyawan. Namun hal 
tersebut sepertinya sangat sulit diwujudkan di perusahaan yang memiliki jumlah karyawan yang terbatas seperti pada PT.VMC Fishing Tackle Indonesia dimana sejumlah posisi yang strategis telah ditempati karyawan yang berstatus permanen sehingga memperkecil kemungkinan karyawan kontrak untuk menduduki posisi strategis tersebut. Maka hal ini dianggap menjadi salah satu faktor yang membuat karyawan tidak termotivasi untuk meningkatkan kinerjanya selain dari aspek disiplin kerja dan lingkungan kerja.

Jika variabel-variabel yang sudah dijabarkan diatas sudah dijalankan dengan baik tentu itu akan berdampak tinggi pula terhadap kinerja nyang akan dihasilkan oleh karyawan tersebut,akan tetapi sering kali perusahaan kurang dapat memahami apakah aspekaspek tersebut sudah cukup untuk memotivasi karyawan untuk dapat meningkatkan kinerja kerjanya.

\section{METODE PENELITIAN}

Penelitian memakai metode kuantitatif. Dimana Penelitian kuantitatif adalah metode penelitian yang berdasarkan pada filsafat Positivism, digunakan untuk meneliti populasi atau sampel tertentu, cara mengumpulkan data memakai instrument penelitian, analisis datanya bersifat kuantitatif/ statistik, itu semua bertujuan untuk mencoba hipotesis yang sudah ditetapkan. Penelitian ini dilakukan pada populasi atau sampel tertentu yang refresentatif. Proses penelitian ini bisa di bilang itu sifatnya deduktif, itu bertujuan untuk menjawab rumusan masalah menggunakan konsep atau teori supaya bisa dirumuskan hipotesisnya. Selanjutnya hipotesis diuji dengan ngumpulin data dilapangan. Untuk mengumpulkan data bisa memakai instrument penelitian. Data yang sudah dikumpulkan sehabis itu dianalisis secara kuantitatif pakai statistik deskriptif, dan bisa di tarik kesimpulan hipotesis yang dirumuskan tersebut terbukti atau tidak. Penelitian kuantitatif pada umumnya di lakukan pada sampel yang diambil secara acak, dan kesimpulan hasil penelitian bisa digeneralisasi pada populasi dimana sampel itu diambil. Populasi untuk Penelitian ini yaitu karyawan PT.VMC Fishing Tackle Indonesia berjumlah 98 karyawan, Berdasarkan penelitian ini karena jumlah populasinya tidak lebih besar dari 100 orang responden, maka peneliti mengambil 100\% jumlah populasi yang ada pada PT.VMC Fishing Tackle Indonesia yaitu sebanyak 98 orang responden. Metode untuk mengumpulkan data mengunakan metode primer dan sekunder, dikumpulkan sesuai dengan jawaban responden dengan menggunakan kuesioner, dan data sekunder didapat dari studi perpustakaan dan studi dokumen yakni ngumpulin data sesuai dengan buku-buku literatur jurnal dan internet. Data yang didapat selanjutnya melakukan pengujian untuk instrument yang akan digunakan. Pengujian instrument untuk penelitian ini mencakup uji validitas data,reliabilitas data dan normalitas data menggunakan program software statistical product and service solution (SPSS) versi 20.

\section{KAJIAN PUSTAKA}

\section{Pengertian Manajemen Sumber Daya Manusia}

Manajemen Sumber Daya Manusia adalah ilmu untuk bisa mengatur hubungan dan peran anggota organisasi supaya efektif dan efisien agar dapat terwujudnya tujuan perusahaan, karyawan, dan masyarakat (Melayu Hasibuan, 2016).

\section{Disiplin Kerja}

Disiplin kerja merupakan bagian atau variabel yang sangat penting dalam pengembangansumber daya manusia.Oleh 
karena itu, disiplin kerja diperlukan dalam suatu organisasi agar tidak terjadi keteledoran, penyimpangan atau kelalaian yang menyebabkan terjadinya pemborosan dalam melakukan pekerjaan.Nurcahyo (2011). Dengan indikator tujuan dan kemampuan, teladan pimpinan,balas jasa, keadilan, waskat, sanksi/hukum, ketegasan

\section{Lingkungan Kerja}

Lingkungan kerja adalah suatu tempat yang ada banyak kelompok yang mana di dalamnya ada beberapa fasilitas pendukung untuk bisa sampai pada tujuan uang di mau perusahaan, sesuai dengan visi dan misi perusahaan. Sedarmayanti (2013). Dimana lingkungan kerja punya indikator Suhu, udara di tempat kerja, ruang di tempat kerja, sirkulasi di tempat kerja, tingkat pencahayan di tempat kerja, hubungan antar karyawan di tempat kerja, hubungan karyawan dengan pemimpin perusahaan di tempat kerja. (Sedarmayanti 2011).

\section{Penilaian Prestasi Kerja}

Penilaian prestasi kerja adalah nilai rasio hasil kerja nyata dengan standar kualitas dan standar kuantitas yang dipunya oleh setiap karyawan yang kerja. Menetapkan kebijaksanaan berarti apakah karyawan akan dipromosikan supaya bisa naik jabatan, didemosikan, atau gaji dinaikkan. Dan penilaian prestasi kerja memiliki beberapa indikator diantaranya kreativitas, kedisiplinan, dan kepemimpinan.

\section{HASIL PEMBAHASAN}

Pengaruh Disiplin kerja, Lingkungan Kerja, dan Penilaian Prestasi Kerja terhadap Kinerja Karyawan pada PT. VMC Fishing Tackle Indonesia.

\section{Hasil Uji Rekresi Linear Berganda}

setiap 1 skor penerapan Disiplin Kerja bertambah dengan satu - satuan maka itu bisa dapat mempengaruhi Kinerja dari setiap Karyawan sebesar -0,118 dan setiap 1 skor Lingkungan kerja bertambah akan bisa mempengaruhi Kinerja setiap Karyawan sebesar 0,551 , selanjutnya setiap 1 skor Penilaian Prestasi Kerja bertambah maka itu bisa mempengaruhi Kinerja setiap Karyawan sebesar 0,249, selebihnya di pengaruhi oleh faktor lain.

\section{Hasil Uji -T}

Hasil Uji-T didapatkan hasil bahwa Variabel Disiplin Kerja (X1) berpengaruh sebesar 0,861 untuk Kinerja karyawan (Y) dan signifikan sebesar 0,391 . Yang mana $T$ hitung $=-0,861<\mathrm{t}$ tabel $=1,66055$ atau signifikan $<0,05$, dan dapat disimpulkan bahwa Ho ditolak dan Ha diterima yaitu Disiplin Kerja (X1) berpengaruh secara signifikan untuk Kinerja setiap Karyawan (Y).

Dan $\mathrm{T}$ hitung yang di dapat untuk variabel Lingkungan Kerja (X2) punya pengaruh sebesar 4,535 untuk Kinerja Karyawan (Y) dan signifikan 0,000 . bisa dikatakan bahwa $\mathrm{T}$ hitung $=4,535>\mathrm{T}$ tabel $=1,66055$ atau signifikan $<0,05$, dan kesimpulan yang bisa di ambil bahwa Ho ditolak Ha diterima yaitu Lingkungan Kerja (X2) punya pengaruh yang signifikan untuk Kinerja setiap Karyawan(Y).

Selanjutnya dan $\mathrm{T}$ hitung yang di dapat untuk variabel Penilaian Prestasi Kerja (X3) punya pengaruh sebesar 2,128 untuk Kinerja setiap Karyawan (Y) dan signifikan 0,036 . dapat disimpulkan bahwa $\mathrm{T}$ hitung $=2,128 \mathrm{>}$ $\mathrm{T}$ tabel $=1,66055$ atau signifikan kecil dari 0,05, maka hasil dari kesimpulan diatas adalah Ho ditolak Ha diterima yaitu Penilaian Prestasi Kerja (X3) punya pengaruh yang signifikan untuk Kinerja setiap Karyawan(Y).

\section{Hasil Uji -F}

Hasil uji $\mathrm{F}$ memperlihatkan nilai $\mathrm{F}$ sebesar 23,182 (F hitung) > 2,70 (F tabel) dan nilai signifikan sebesar $0,000<0,5$ jadi keputusan yang bisa di ambil adalah Ho ditolak dan $\mathrm{Ha}$ diterima. Bisa dikatakan bahwa variabel Disiplin Kerja (X1), 
Lingkungan Kerja (X2), dan Penilaian Prestasi kerja (X3) itu mempunyai signifikan secara keseluruhan untuk Kinerja setiap Karyawan (Y).

\section{Hasil Uji Koefisien Determinasi}

Dimana memperlihatkan nilai $\mathrm{R}$ Square sebesar 0,407 artinya korelasi antara variabel Disiplin Kerja (X1), Lingkungan Kerja (X2), dan Penilaian Prestasi Kerja (X3) terhadap variabel Kinerja Karyawan (Y) dalam model regresi sebesar 42,5\%. Hasil pengujian nilai R Square sebesar 0,425 atau 42,5\% dari Kinerja Karyawan dapat dipengaruhi oleh Disiplin Kerja (X1), Lingkungan kerja (X2), dan Penilaian Prestasi Kerja (X3). Sisanya 57,5 \% Kinerja Karyawan dipengaruhi oleh variabelvariabel lain yang tidak dijelaskan dalam penelitian ini.

\section{KESIMPULAN DAN SARAN}

\section{KESIMPULAN}

1. Disiplin Kerja punya pengaruh untuk Kinerja setiap Karyawan pada PT. VMC Fishing Tackle Indonesia.

2. Lingkungan Kerja punya berpengaruh juga untuk Kinerja setiap Karyawan pada PT. VMC Fishing Tackle Indonesia.

3. Penilaian Prestasi Kerja punya berpengaruh juga untuk Kinerja setiap Karyawan pada PT. VMC Fishing Tackle Indonesia.

4. Disiplin Kerja, Lingkungan Kerja, Penilaian Prestasi Kerja berpengaruh secara keseluruhan untuk Kinerja setiap karyawan pada PT. VMC Fishing Tackle Indonesia.

\section{SARAN}

berdasarkan beberapa kesimpulan diatas peneliti memberikan beberapa saran untuk perbaikan penelitian dimasa yang akan datang dan pengembangan pendidikan dalam manejerial sebagai berikut :

1. Disiplin kerja dapat ditingkatkan melalui perbaikan sistem manajemen sumber Daya Manusia yang sudah ada dan kesadaran masing-masing individu untuk meningkatkan Disiplin Kerja sehingga Kinerja Karyawan juga akan meningkat.

2. Lingkungan Kerja yang nyaman akan sangat berpengaruh terhadap Kinerja Karyawan, maka ini adalah tugas penting pihak manajemen untuk terus memperbaiki dan menata lingkungan kerja sehingga akanada timbal balik yang akan didapatkan oleh pihak perusahaan dengan adanya peningkatan Kinerja Karyawan.

3. Penilaian Prestasi Kerja juga harus menjadi perhatian penting oleh pihak manajemen dimana pengapresiasian perusahaan terhadap karyawan sangat mempengaruhi Kinerja Karyawan, dimana karyawan yang memperoleh penghargaan akan termotivasi untuk meningkatkan kualitas ataupun kinerja kerjanya sebaliknya saat perusahaan memberikan penilaian yang kurang baik terhadap seorang karyawan maka karyawan tersebut juga akan termotivasi untuk memperbaiki dirinya.

4. Secara simultan Disiplin Kerja, Lingkungan Kerja, dan Penilaian Prestasi Kerja kasih pengaruh positif signifikan untuk Kinerja setiap karyawan, tetapi perlu diteliti untuk mencari tahu masih ada faktor-faktor lain yang bisa mempengaruhi Kinerja 
jurnal $\mathrm{B} \perp \mathrm{I} I \mathrm{I}$ Prodi Manajemen
UNIVERSITAS RIAU KEPULAUAN BATAM

setiap Karyawan selain factor - faktor yang di ambil peneliti.

\section{DAFTAR PUSTAKA}

Dr Sudaryono. 2015. Study Kelayakan bisnis. Lentera Ilmu Cendikia ; Jakarta pusat

Hambali, Muhammad 2015, Pengaruh Penerapan Sistem Informasi ERP (Microsoft Dynamics dan Efesiensi Kerja terhadap Produktivitas Kerja. PT. Osi

Electronics. Batam.

Indriani, Diah Suwondo \& , 2015.Hubungan Lingkungan kerja, Disiplin Kerja dan Kinerja karyawan,17, 35-144.

Januari, Cindi Ismi, Hamidah Nayati Utami, Ika Ruhana 2015, Pengaruh Penilaian Prestasi Kerja terhadap Pepuasan Kerja dan Prestasi Kerja,PT. Telekomunikasi Indonesia, Tbk.vol 24

Manik,Sudarmin, Nova Syafrina. 2018, Pengaruh Insentif dan Kepuasan Kerja terhadap Kinerja Karyawan, Hotel Grand Zuri Duri,.vol 4

Ratna Dewi, Sri 2012, Pengaruh Pelaksanaan Penilaian Prestasi Kerja dan Motivasi Terhadap Kepuasan Kerja.PT.Batamindo Investment Cakrawala.

Sedarmayanti, 2013, Manajemen Sumber Daya Manusia Repormasi
Volume 6 No. 2 Tahun 2019

P-ISSN 2252-5262

E-ISSN 2614-499

Birokrasi dan Manajemen Pegawai Negeri Sipil. Bandung. PT. Refika Aditama.

Sedarmayanti, 2011, Tata Kerja dan Produktivitas Kerja: Suatu Tinjauan Dari Aspek Ergonomi atau Kaitan Antara Manusia Dengan Lingkungan Kerjanya. Cetakan Ketiga. Bandung: Mandar Maju.

S.P, Hasibuan, Melayu.2013. Manajemen Sumber Daya Manusia. Jakarta edisi revisi: PT. Bumi Aksara.

Sugiyono. 2013. Metode Penelitian Kuntitatif Kualitatif dan R\&D. Bandung: Alfabeta.

Syafrina, Nova. 2016. Pengaruh Disiplin Kerja terhadap Kinerja Karyawan. PT Suka Fajar. Pekan baru

Winarni, Rina, dkk. 2016. Pengaruh Penilaian Prestasi Kerja dan Kompensasi terhadap Kinerja Tenaga Teknis Kefarmasian NonPNS Instalasi Farmasi. RSUP Dr. Hasan Sadikin

Yamanie, Ibnu Yarham, Syaharuddin Y. 2016 Pengaruh Penilaian Prestasi Kerja, Komitmen Organisasi dan Disiplin Kerja Terhadap Kinerja Karyawan. PT.Pelabuhan Indonesia IV Cabang Samarinda.vol 8 